\title{
Acute Infection of Viral Pathogens and Their Innate Immune Escape
}

\author{
Kul Raj Rai', Prasha Shrestha', Bincai Yang ${ }^{1}$, Yuhai Chen², Shasha Liu', \\ Mohamed Maarouf ${ }^{2}$ and Ji-Long Chen ${ }^{1,2 *}$ \\ ${ }^{1}$ Key Laboratory of Fujian-Taiwan Animal Pathogen Biology, College of Animal Sciences, Fujian Agriculture and Forestry \\ University, Fuzhou, China, ${ }^{2}$ CAS Key Laboratory of Pathogenic Microbiology and Immunology, Institute of Microbiology, \\ Chinese Academy of Sciences (CAS), Beijing, China
}

\section{OPEN ACCESS}

Edited by:

Christiane Moog,

Institut National de la Santé et de la Recherche Médicale (INSERM),

France

Reviewed by:

Malin Flodström-Tullberg, Karolinska Institutet (KI), Sweden

Irene Ramos,

Icahn School of Medicine at Mount

Sinai, United States

${ }^{*}$ Correspondence:

Ji-Long Chen

chenj@@im.ac.cn

Specialty section:

This article was submitted to

Virology,

a section of the journal

Frontiers in Microbiology

Received: 25 February 2021

Accepted: 04 May 2021

Published: 22 June 2021

Citation:

Rai KR, Shrestha P, Yang $B$,

Chen Y, Liu S, Maarouf M and

Chen J-L (2021) Acute Infection of Viral Pathogens and Their Innate

Immune Escape.

Front. Microbiol. 12:672026 doi: 10.3389/fmicb.2021.672026
Viral infections can cause rampant disease in human beings, ranging from mild to acute, that can often be fatal unless resolved. An acute viral infection is characterized by sudden or rapid onset of disease, which can be resolved quickly by robust innate immune responses exerted by the host or, instead, may kill the host. Immediately after viral infection, elements of innate immunity, such as physical barriers, various phagocytic cells, group of cytokines, interferons (IFNs), and IFN-stimulated genes, provide the first line of defense for viral clearance. Innate immunity not only plays a critical role in rapid viral clearance but can also lead to disease progression through immune-mediated host tissue injury. Although elements of antiviral innate immunity are armed to counter the viral invasion, viruses have evolved various strategies to escape host immune surveillance to establish successful infections. Understanding complex mechanisms underlying the interaction between viruses and host's innate immune system would help develop rational treatment strategies for acute viral infectious diseases. In this review, we discuss the pathogenesis of acute infections caused by viral pathogens and highlight broad immune escape strategies exhibited by viruses.

\section{Keywords: viral pathogens, acute infection, innate immunity, innate immune escape, non-structural protein}

\section{INTRODUCTION}

Viral pathogens are infectious particles containing either DNA or RNA as their genome. A large number of viruses belonging to various families cause rampant disease in human beings, ranging from mild and self-limiting to acute fatal diseases (Herrington et al., 2015; Keighley et al., 2015; Jacob et al., 2020). Various viral families, such as Filoviridae, Arenaviridae, Bunyaviridae, Paramyxoviridae, Coronaviridae, Orthomyxoviridae, Flaviviridae, Togaviridae, Hepeviridae, and so forth, infect humans and/or animals. Unfortunately, emerging and re-emerging viral pathogens often cause catastrophic pandemics that may take millions of human lives. For example, the most devastating "Spanish flu" pandemic in 1918 took over 50 million lives. The subsequent emergence

\footnotetext{
Abbreviations: AP-1, Activator protein 1; EV, Extracellular vesicles; HERV, Human endogenous retrovirus; HIV, Human immunodeficiency virus; HSV, Herpes simplex virus; IFITM, Interferon-induced transmembrane protein; IKK, I-kappaB kinase; KSHV, Kaposi's sarcoma-associated herpesvirus; MAVS, Mitochondrial antiviral signaling protein; MHV, Mouse hepatitis virus; MX1, Myxovirus Resistance Protein 1; MyD88, Myeloid differentiation primary response 88; NF-kB, Nuclear factor kappa-light-chain-enhancer of activated B cells; RIP1, Receptor interacting protein; SIV, Simian immunodeficiency virus; Syk, Spleen tyrosine kinase; TBK1, TANK-binding kinase 1; TRAF, TNF receptor associated factors; TRIF, TIR-domaincontaining adapter-inducing interferon- $\beta$.
} 
of flu pandemics, such as "Asian flu" and "Hong Kong flu" in 1957 and 1968, respectively, killed about three million people (Salomon and Webster, 2009). During 2002 and 2003, a novel severe acute respiratory syndrome coronavirus (SARS-CoV) infected over 8,000 people, causing 774 deaths in 27 countries (World Health Organization, 2018). A new virulent Influenza A Virus (IAV) H1N1 strain (H1N1pdm09) emerged in 2009 that killed $\sim 151,700-575,400$ people worldwide (Centre for Disease Control and Prevention (CDC), 2012). A new avian IAV strain (H7N9), "Bird flu," and the Middle East respiratory syndrome (MERS)-CoV in 2013 also emerged (To et al., 2013). Some viruses re-emerged after a number of years, such as the reemergence of the Ebola virus (EBOV) in 2014 (Shen et al., 2015), resurgences of the Zika virus (ZIKV) in 2015 and 2016 (Shuaib et al., 2016), and so forth (Chauhan et al., 2020; Guo, 2020). The ongoing pandemic caused by SARS-CoV-2 has already ravaged humanity and is still on the rise across the globe. Health challenges and economic consequences caused by the ongoing Covid-19 pandemic are potentially devastating and may remain an enduring puzzle. Therefore, a better understanding of the complex underlying mechanisms of viral pathogenesis caused by acute infections is truly important to the human community.

Innate immunity is a critical first line of defense against viral invasion. A well-specialized immune system consisting of distinct physical and chemical barriers, such as mucosal surfaces, skin, and their secretions, counter against viral invasion during viral entry into the host. Viruses are further sensed by various pattern recognition receptors (PRRs) after their entry, which leads to the activation of innate immune signaling pathways that control the production of interferons (IFNs), pro-inflammatory cytokines, and chemokines. Type I and III IFNs produced by various types of cells stimulate the expression of hundreds of genes, collectively known as IFN-stimulated genes (ISGs), which prime cells into an antiviral state (Iwasaki and Pillai, 2014; Chen et al., 2018). Secreted pro-inflammatory cytokines cause local and systemic inflammation. Chemokines produced at the site of infection may recruit additional immune cells, including neutrophils, monocytes, and natural killer cells (Christensen and Thomsen, 2009; Chen et al., 2018). Then, virus-infected cells could be targeted by immune cells, which mediates viral clearance (Iwasaki and Pillai, 2014). An acute viral infection is characterized by sudden or rapid onset of disease that may be fatal. Viral clearance during acute infection correlates with rapid induction of innate immunity, especially induction of ISGs, and subsequent induction of adaptive immune responses (Heim and Thimme, 2014). On the other hand, viruses are ever-evolving and can emerge and re-emerge into newer/novel virulent strains. The emergence of viral variants with increased adaptability and/or virulence indicates that viruses are acquiring new strainspecific mechanisms of immune escape. Viruses can develop multiple tactics to subvert innate immune surveillance and escape detection by innate immune sensors, leading to suppression of PRRs and their downstream signaling cascades to establish a successful infection. For instance, non-structural proteins of influenza and members of Flaviviridae viruses deploy numerous tactics to potently inhibit type I IFN signaling (Marc, 2014; Li et al., 2015; Chen et al., 2017). SARS-CoV-2 deregulates type
I IFN responses through multiple mechanisms (Acharya et al., 2020). ZIKV circumvents host innate immunity by targeting the adaptor proteins MAVS and MITA (Li et al., 2019). Enteroviruses brilliantly exploit their viral proteinase $\left(3 \mathrm{C}^{\text {pro }}\right.$ and $\left.2 \mathrm{~A}^{\text {pro }}\right)$ to cleave PRRs (RIG-I, MDA5) and immune adaptor molecules (MAVS and TRIF), and thereby dampen the production of type I and III IFNs (Mukherjee et al., 2011; Feng et al., 2014; Lind et al., 2016). Cooperation among non-structural proteins (NS1, NS4B, and NS2B3) of ZIKV appeared to attenuate antiviral immunity (Wu et al., 2017). In this review, we describe the pathogenesis of acute viral infections in relation to host innate immunity and discuss how viruses escape innate immune surveillance.

\section{PATHOGENESIS OF ACUTE VIRAL INFECTIONS}

Being obligated intracellular parasitic infectious particles, viruses replicate only inside their specific host cell or tissue. For viruses to cause diseases, they must first infect their specific host, replicate efficiently within the host, and damage targeted tissues. Viral pathogenesis is complex and disease outcomes are determined by multiple factors (MacLachlan and Dubovi, 2017). Viruses rely on numerous host factors (determinants) to replicate efficiently in the host to cause disease (MacLachlan and Dubovi, 2017; Long et al., 2019; Gerold et al., 2020). Some hosts are highly susceptible to viral infection, while some are resistant. Differential host susceptibility to viral infection and disease progression depends on both viral infectivity (virulence) and host responses (Long et al., 2019; Gerold et al., 2020). Of those host responses, innate immunity plays a critical role in viral clearance and disease progression. During viral infection, various factors including delicate and dynamic equilibrium between pro-inflammatory and anti-inflammatory responses, immune cell activation and deactivation, and IFNs upregulation and IFN-reversion to the baseline, play important roles in viral pathogenesis and progression of disease (Virgin et al., 2009; Osburn et al., 2013; Maarouf et al., 2018; Blanco-Melo et al., 2020). For example, an imbalanced response that is characterized by low levels of type I and III IFNs juxtaposed to elevated chemokines and high expression of IL-6 to SARS-CoV-2 drives the development of COVID-19 (Blanco-Melo et al., 2020).

An acute viral infection can be resolved quickly by immune responses exerted by the host. For example, acute Hepatitis B Virus (HBV) infection can be spontaneously resolved in more than $90 \%$ of infected adults, although HBV can sometimes result in chronic persistent infection (Shin et al., 2016). The inflammatory response must be well-regulated in the course of viral clearance. However, excessive inflammatory responses can be lethal. Elevated levels of a broad array of pro-inflammatory cytokines and chemokines have been observed in diseases caused by various acute viral infections, such as EBOV disease, severe lung injury by infection of IAV, respiratory syncytial virus (RSV), and SARS-CoV-2 (Virgin et al., 2009; Shin et al., 2016; Troy and Bosco, 2016; Maarouf et al., 2018; Blanco-Melo et al., 2020). Acute respiratory infections are the leading cause of global disease (Troy and Bosco, 2016). Immune responses and disease 
outcomes in acute HAV (Hepatitis A Virus), HBV, and HCV infections have been previously described (Shin et al., 2016). Clinical manifestations, etiology, and outcome of various viral diseases caused by a large group of numerous viral infections have been described/reviewed elsewhere (Whitton et al., 2005; Ascenzi et al., 2008; Gould and Solomon, 2008; Ramos-Casals et al., 2008; Rojek and Kunz, 2008; Newton et al., 2016; Troy and Bosco, 2016; Zuberbier et al., 2018).

\section{INNATE IMMUNITY}

\section{Innate Detection of Viral Infections}

Immediately after viral infection, elements of innate immunity, such as physical barriers, various phagocytic cells, group of cytokines, IFNs, and IFN-stimulated genes, provide the first line of defense for viral clearance. Physical barriers, such as mucosa, skin, mucous membranes, tears, earwax, mucus, and stomach acid provide preliminary defense against invading viruses (Sanders et al., 2011; Doran et al., 2013; Chen et al., 2018). If viral invaders breach physical barriers, viruses are detected/sensed by germline-encoded immune molecules PRRs (Lazear et al., 2013; Iwasaki and Pillai, 2014; Chen et al., 2018; Chiang and Liu, 2019). Toll-like receptors (TLRs), such as TLR2/3/4/7/8/9 are important immune detectors involved in the induction of innate immunity (Kawai and Akira, 2010). TLR2 and 4 detect extracellular viral proteins at the cell surface. Intracellular viral dsRNA, ssRNA, and DNA are recognized by TLR3, TLR7, TLR8, and TLR9, at intracellular endosomal compartments during endocytosis and autophagy (Kawai and Akira, 2010; Maarouf et al., 2018). Retinoic acid-inducible gene I (RIG-I) like receptors, including RIG-I and melanoma differentiationassociated protein 5 (MDA5), are key intracellular sensors of viral RNA (Kawai and Akira, 2010; Morgan Brisse, 2019). RIGI plays an important role in the detection of several viruses, such as orthomyxoviruses, rhabdoviruses, and arenaviruses, and MDA5 preferentially detects picornaviruses. Additionally, many other viruses, such as flaviviruses, paramyxoviruses, reoviruses, and others are also detected by both RIG-I and MDA5 (Morgan Brisse, 2019). Cumulative pieces of evidence have also shown that paramyxoviruses, some flaviviruses [for example, Dengue Virus (DENV) and West Nile Virus (WNV)], and reoviruses, may be sensed by both RIG-I and MDA5 (Kawai and Akira, 2010; Goubau et al., 2013; Chan and Gack, 2016; Morgan Brisse, 2019). Well-known viral pathogens responsible for acute respiratory infections, such as SARS-CoV, SARS-CoV-2, and MERS-CoV are detected by endosomal PRRs, including TLR3 and 7, and/or cytoplasmic sensors, such as RIG-I and MDA5 (Felsenstein et al., 2020; Liu et al., 2020). NOD-like receptors (NLRs) are a large family of intracellular PRRs. Members of the NLR family assemble into large multiprotein complexes, termed inflammasomes. Many viruses, including rotavirus, Sendai Virus (SeV), and IAV, can activate inflammasomes (Shrivastava et al., 2016). Cyclic-GMP-AMP (cGAMP) synthase (cGAS) and gamma-IFN-inducible protein 16 (IFI16) are well characterized as intracellular detectors of DNA viruses and viral DNA intermediates (Koyama et al., 2008; Ma et al., 2018).

\section{Innate Immune Signaling}

Innate immune signaling is initiated by sensing specific viral components, called pathogen associate molecular patterns (PAMPs), such as viral dsRNA, ssRNA, DNA, transcription products, and other viral components including replication intermediates. The sense of PAMPs by PRRs leads to the activation of downstream molecules including mitochondrial antiviral signaling protein (MAVS), stimulator of IFN genes (STING) or MYD88, and transcription factors, such as interferon regulatory factors (IRF3/5/7), NF-kB, AP1, and so forth (Koyama et al., 2008; Ishikawa et al., 2009; Kawai and Akira, 2010; Rathinam and Fitzgerald, 2011; Jensen and Thomsen, 2012; Goubau et al., 2013; Lazear et al., 2013; Iwasaki and Pillai, 2014; Goraya et al., 2015; Chan and Gack, 2016; Shrivastava et al., 2016; Chen et al., 2018; Ma et al., 2018; Chiang and Liu, 2019; Morgan Brisse, 2019; Felsenstein et al., 2020; Liu et al., 2020). The PRR-mediated signaling pathways ultimately lead to the secretion of numerous antiviral molecules, including type I and type III IFNs, and other pro-inflammatory cytokines and chemokines (Koyama et al., 2008; Ishikawa et al., 2009; Kawai and Akira, 2010; Rathinam and Fitzgerald, 2011; Jensen and Thomsen, 2012; Goubau et al., 2013; Lazear et al., 2013; Iwasaki and Pillai, 2014; Goraya et al., 2015; Chan and Gack, 2016; Shrivastava et al., 2016; Chen et al., 2018; Ma et al., 2018; Chiang and Liu, 2019; Morgan Brisse, 2019; Felsenstein et al., 2020; Liu et al., 2020). The secreted IFNs bind to their respective receptors and activate Janus protein tyrosine kinase-signal transducer and activator of transcription (JAK-STAT) pathway (Majoros et al., 2017) that results in the production of hundreds of downstream antiviral ISGs, such as MX1, ISG15, IFITM3, and viperin, which establish an antiviral state to impede virus infection (Iwasaki and Pillai, 2014; Schoggins, 2014; Figure 1). Recently, activation of the innate immunity independently of cytokine signaling through RIG-I/MAVS/Syk/STAT1 pathway at the early stage of viral infection has also been reported (Liu et al., 2021). The mechanistic basis of innate immune signaling induced by several viral infections has been extensively reviewed elsewhere (see review papers Koyama et al., 2008; Ishikawa et al., 2009; Kawai and Akira, 2010; Rathinam and Fitzgerald, 2011; Jensen and Thomsen, 2012; Goubau et al., 2013; Lazear et al., 2013; Iwasaki and Pillai, 2014; Schoggins, 2014; Goraya et al., 2015; Chan and Gack, 2016; Shrivastava et al., 2016; Majoros et al., 2017; Chen et al., 2018; Ma et al., 2018; Chiang and Liu, 2019; Morgan Brisse, 2019; Felsenstein et al., 2020; Liu et al., 2020, 2021).

\section{Roles of Interferons in Antiviral Responses}

Interferons (IFNs), a family of cytokines, are critical elements of innate immunity responsible for rapid and efficient viral clearance (Fensterl and Sen, 2009). Virtually all nucleated cells could express IFNs during viral infection and IFN production is the key antiviral process of innate immunity during viral infection. Type I (IFN- $\alpha / \beta)$ and Type III IFNs are principal IFNs produced during viral infection as a key part of the innate immune response. The typical feature of IFNs is to induce upregulation of a wide array of intracellular antiviral 


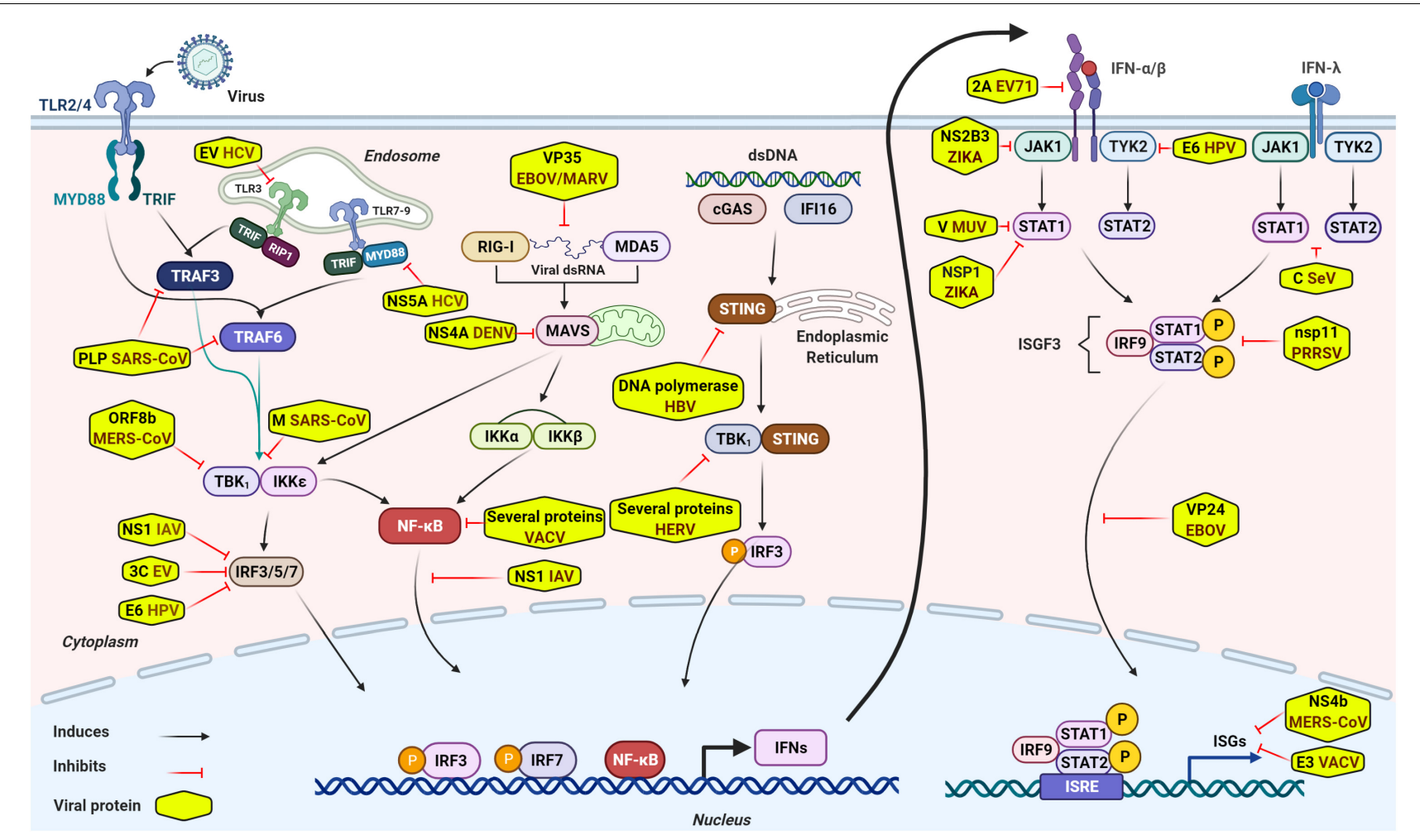

FIGURE 1 | General overview of intracellular innate immune signaling and some representative viral immune escape mechanisms. Sensing virus by PRRs initiates innate immune signaling through the hierarchical activation of PRRs family-specific adaptor proteins (TRIF, MAVS, STING, MYD88, and so forth) to activate transcriptional factors, such as IRF3/5/7, NF-kB, and others. Activated transcriptional factors translocate into nucleus and induce robust expression of IFNs. Secreted IFNs bind to their respective receptors and activate JAK-STAT signaling and form a transcriptional factor called ISGF3. ISGF3, then, translocates into nucleus to induce expression of numerous antiviral effectors (ISGs) to impede viral infection. Although antiviral innate immunity consists of well-equipped arsenals to impede viral infection and invasion, viruses circumvent or escape from these antiviral arsenals to establish successful infection through several mechanisms. Of these escape mechanisms, viral components inhibit innate immune signaling by diversified tactics, such as interacting directly or indirectly with crucial innate elements, targeting and cleaving adaptor proteins involved in innate immune signaling or interference of IFN signaling, degradation of JAK/STAT components, and so forth. Some representative viral immune escape tactics are shown in the Figure 1.

effectors called ISGs through JAK-STAT signal pathway (Fensterl and Sen, 2009; Schoggins, 2014; Majoros et al., 2017; Paul et al., 2018). Type I and type III IFNs bind to their respective receptors on the infected cell and neighboring cells, which leads to activation of JAK-STAT pathway and nuclear translocation of STAT1/STAT2/IRF9 (ISGF3) (Reviewed in Fensterl and Sen, 2009; Schoggins, 2014; Paul et al., 2018) and results in induction of numerous ISGs, such as Mx proteins, ISG15, protein kinase PKR, 2'-5'-oligoadenylate synthetases (OAS), ribonuclease L (RNaseL), IFN-inducible dsRNA-dependent protein kinase (PKR), adenosine deaminase RNA-specific and apolipoprotein B mRNA-editing enzyme, catalytic polypeptide 3 , and others to establish an antiviral state (Iwasaki and Pillai, 2014; Chen et al., 2018). Of note, some ISGs, such as OAS and PKR, are further activated by dsRNA, which, in turn, inhibit viral replication by various mechanisms (Ishikawa et al., 2009; Iwasaki and Pillai, 2014; Chen et al., 2018). Additionally, IFNs may also exert immunomodulatory functions that affect cell migration, crosspresentation, $\mathrm{CD}^{+} \mathrm{T}$ cell stimulation or $\mathrm{CD}^{+} \mathrm{T}$ cell clonal expansion, and $\mathrm{B}$ cell activation, and enhance antiviral humoral responses (Iwasaki and Pillai, 2014). Thus, before the effective adaptive immunity is initiated, IFN-mediated innate immune response plays critical roles in eliminating virus invasion (Iwasaki and Pillai, 2014). Although viral infection induces the rapid expression of IFNs and antiviral effectors, at the same time, viral components can suppress IFNs signaling. Theoretically, virusinduced robust IFNs production, IFN-reversion to baseline by viral antagonisms, and optimal ISGs expression could establish a steady, delicate, and dynamic equilibrium. However, destruction of such a steady state, particularly in acute viral infection, by hyper-production of IFNs and hyper-effective immune evasion is the primary cause of viral pathogenesis (Maarouf et al., 2018; Blanco-Melo et al., 2020). Both hyper-production of IFNs and hyper-effective immune evasion are disadvantageous to the host. Imbalanced levels of IFNs expression and differential ISGs production differ across type of viruses, which also determines the viral pathogenesis. For instance, among three Hepatitis (A, $\mathrm{B}$, and $\mathrm{C}$ ) viruses, $\mathrm{HCV}$ infection induces the robust expression of a large number of ISGs, whereas HAV infection minimally induces ISG expression and HBV infection might not induce ISG expression (Shin et al., 2016). Moreover, viruses are ever-evolving to escape away from innate immunity, particularly at acute 
infection. For example, IFITM is a critical antiviral ISG against several viruses including Human Immunodeficiency Virus (HIV1), however, transmitted founder HIV-1viruses are uniquely IFITM resistant, a property that is lost during chronic infection. This is in part due to escape mutations acquired in response to autologous neutralizing responses (Foster et al., 2016).

\section{CYTOKINE STORM CAUSED BY ACUTE VIRAL INFECTION}

Optimal activation of innate immunity in the course of viral infection is very important for viral clearance. However, an acute viral infection usually causes over-activation of innate immunity. Such over-activation may induce robust and hyperproduction of IFNs, proinflammatory and anti-inflammatory cytokine, and chemokines, including excessive secretion of TNF$\alpha$, vascular endothelial growth factors (VEGF-A), IL-1, IL-6, IL-10, IL-8, CCL2, CXCL10, and so on, leading to cytokine storms (Wauquier et al., 2010; Liu et al., 2016; Srikiatkhachorn et al., 2017; Teijaro, 2017; Blanco-Melo et al., 2020; Gerges Harb et al., 2020; Mahmudpour et al., 2020; Vabret et al., 2020). Cytokine storms released during acute viral infection can result in single or multiple organ damage and even death (Wauquier et al., 2010; Liu et al., 2016; Srikiatkhachorn et al., 2017; Teijaro, 2017; Maarouf et al., 2018; Blanco-Melo et al., 2020; Gerges Harb et al., 2020; Mahmudpour et al., 2020; Vabret et al., 2020). For example, in COVID-19, the cytokine storm is an important factor leading to the death of many patients (Mahmudpour et al., 2020; Vabret et al., 2020). Cytokine storms caused by acute viral infection, such as influenza virus, coronavirus, Ebola virus, dengue virus, and so forth have been extensively reviewed elsewhere (Wauquier et al., 2010; Liu et al., 2016; Srikiatkhachorn et al., 2017; Teijaro, 2017; Gerges Harb et al., 2020; Mahmudpour et al., 2020; Vabret et al., 2020).

\section{VIRAL INNATE IMMUNE ESCAPE STRATEGIES}

Nonetheless, the host is well-equipped with innate antiviral arsenals to eliminate invading viral pathogens; viruses evolved strategies to escape innate immune surveillance. At the early stage of viral entry into the host, viruses breach hosts' physical barriers by various ways. Upon breaching physical barriers, viruses exploit diverse mechanisms to inhibit the activation of PRRs and their downstream signaling cascades, such as concealing their PAMPs, interacting directly or indirectly with crucial innate elements, such as PRRs, transcriptional factors, targeting and cleaving adaptor proteins involved in innate immune signaling or interference of IFN signaling, degradation of JAK/STAT components, and so forth (Table 1). A broad mechanism of viral innate immune escape tactics is discussed below.

\section{Penetrating Physical Barriers}

Physical barriers, such as skin or the surface of the respiratory, genital, or gastrointestinal tracts, including fluid repleted with antimicrobials, neutralizing immunoglobulins, mucus, and the epithelial cell layers, guard viral invaders. Viruses breach such barriers in a multitude of ways. For instance, specific viral proteins interact with cell receptor proteins present in the apical junctional complex to modify the barrier properties of the epithelium (Gonzalez-Mariscal et al., 2009). Interestingly, lower pathogenic avian influenza viruses generally do not cause severe pneumonia because mucus restrains and removes these viruses before approaching lower respiratory tracts, however, highly pathogenic IAV can breach such mucosal barriers (Van Riel et al., 2010). Although the skin is the most important physical barrier, it contains numerous permissive cells for flavivirus infection, such as ZIKV, DENV, and WNV, therefore, these viruses exploit permissive cells at the first site of infection (Garcia et al., 2017). HIV and SIV appear to be capable of flexibly exploiting multiple mechanisms to transit different epithelial barriers and gain access to susceptible target cells to establish a systemic infection (Keele and Estes, 2011).

\section{Escaping From the Recognition From PRRs}

Knowing that viruses are sensed by PRRs, viruses circumvent/minimize PRRs' sensing through numerous viral tactics, such as by sequestering/hiding viral genome, interacting with PRRs, targeting/cleaving adapter proteins, and so on. An in vitro study determined the effect of $\mathrm{HCV}$ proteins (NS3, NS3/4A, NS4B, or NS5A) on the TLR signaling pathways, where cells expressing these proteins were found to inhibit the activation of the TLR2, TLR4, TLR7, and TLR9 signaling pathways (Abe et al., 2007). Several viral proteins can specifically interact with PRRs. For an example, p7 of HCV associates with DNA sensor IFI6-16 (Qi et al., 2017). HBV conceals its genome into the viral capsid to escape away from cGAS sensing (Verrier et al., 2018). The human papillomavirus (HPV) E6 oncoprotein targets USP15 and TRIM25 to suppress RIG-I-mediated innate immune signaling (Chiang et al., 2018). Some viruses have evolved with strategies to modify viral RNAs and viral RNA-binding proteins to escape away from sensing by RIG-I, MDA5 (Bowie and Unterholzner, 2008). Viral dsRNA genome is highly susceptible to recognition by MDA5; both positive-sense RNA viruses and some DNA viruses produce dsRNA intermediate during their replication cycle, while some viruses conceal their dsRNA by encoding dsRNA binding proteins or even sequester viral RNA (Table 1). More interestingly, unlike positive-strand RNA and DNA viruses, negative-sense RNA viruses uniquely do not produce dsRNA intermediates; this unique property minimizes detection by PRRs (Weber et al., 2006). Moreover, a recent report showed that SARS-CoV-2 RNAs are capped at the 5' end and escape recognition from PRRs (Encinar and Menendez, 2020). Viral mechanisms of escaping from PRRs' recognition have been reviewed elsewhere (Weber et al., 2006; Abe et al., 2007; Bowie and Unterholzner, 2008; Chan and Gack, 2016; Qi et al., 2017; Chiang et al., 2018; Verrier et al., 2018; Encinar and Menendez, 2020; Kikkert, 2020; Lhomme et al., 2020; Liu et al., 2020; Zhu and Zheng, 2020). 
TABLE 1 | Representative immune escape strategies.

Viruses

References

\section{Penetrating physical barrier}

Several viruses, such as Coxsackie, Breach mucosa by targeting proteins of the apical junctional complex swine vesicular disease virus, adenovirus, reovirus, and others

ZIKV, DENV, and WNV Breach skin barrier by infecting permissive cells

Penetrate physical barrier in multiple ways

HIV/SIV

Interference with PRRs signaling

$\mathrm{HCV}$

SARS-COV

Extracellular vesicles mask HCV dsRNA to reduce activation of TLR3.

Viral Papain-Like Protease antagonize the TLR7 signaling through removing Lys63-Linked polyubiquitination of TNF receptor-associated factors (TRAF3 and TRAF6)

Marburg virus (MARV) and EBOV VP35 protein binds to viral dsRNA genomes to inhibit viral sensing by RIG-1 and MDA-5.

HBV Escape from cGAS sensing by the packaging of the genome into the viral capsid

Vaccinia virus (VACV) and IAV E3L and NS1 proteins of respective viruses sequester viral dsRNA to escape away from sensing by PRRs

Enterovirus (EV)

Viral proteinases $3 C^{\text {pro }}$ and $2 A^{\text {pro }}$ counteracts PRRs signaling by targeting RIG-I and MDA5, respectively.

HCV NS5A protein inhibits TLR signaling by associating with MYD88

VACV A46R targets multiple Toll-like-interleukin-1 receptor adaptors

\section{Inhibition of transcriptional factors IRF3/7, NF-kB, and AP1}

SARS-COV-2

Suppresses the activation of TRAF3 and TRAF3 and thereby inhibit IRF3/7 and NF-kB activation

MERS-COV Accessory protein ORF8b suppresses MDA5 and TBK1 medicated NF-кB signaling and M protein suppresses type TBK1-dependent phosphorylation of IRF3

IAV NS1 protein inhibits nuclear translocation of IRFs and NF-kB

HPV Interfere in critical ubiquitination events upstream of IRF-3 and NFKB by upregulating the cellular deubiquitinase UCHL1

HCV NS5A viral protein inhibits nuclear translocation of AP-1 by interacting with Grb2

VACV Several viral proteins, such as A46, A49, A52, and others inhibit NF-kB activation by multiple mechanisms.

$\begin{array}{ll}\text { EV } & \text { Viral 3C proteases cleavs IRF7 } \\ \text { SARS-CoV } & \text { Viral M protein inhibits IRF3/7 activation targeting TBK1/IKK } \varepsilon \\ \text { EBOV } & \text { VP35 protein inhibits IRF3 phosphorylation and subsequent dimerization } \\ \text { Human papilloma virus 16 } & \text { Viral E6 oncoprotein binds to IRF3 and inhibits its transcriptional activity } \\ \text { Interference of JAK-STAT signaling } & \text { Viral E6 oncoprotein binds with Tyk2 and impairs JAK-STAT activation } \\ \text { HPV 18 } & \text { V protein induces degradation of STAT-1 and STAT-3 } \\ \text { Mumps virus (MUV) } & \text { Inhibits JAK-STAT signaling by inducing SOCS3 } \\ \text { HSV-1 } & \text { C protein inhibits the phosphorylation of STAT1 and STAT2 } \\ \text { SeV } & \text { Induce STAT2 degradation } \\ \text { ZIKV, DENV } & \end{array}$

ZIKV

EBOV

NS2B3 protein promotes the degradation of Jak1

EBOV VP24 binds to the $\alpha 5$ and $\alpha 6$ subunits of importin, which are the essential components of the nuclear transporter, to block the nuclear translocation of phosphorylated STAT1

Rotavirus

Nipah and Hendra virus NSP1 protein inhibits STAT1 activation

Nucleoproteins inhibit the nuclear accumulation of STAT1 and STAT2 and interfere with their complex formation

Parainfluenza virus type 1

Porcine reproductive and $\mathrm{C}$ protein binds and retains STAT1 in perinuclear aggregates at the late endosome

Nsp11 protein interacts with IRF9 and formation and nuclear translocation of the transcription factor respiratory syndrome virus (PRRSV)

\section{Antagonizing ISGs}

VACV

MERS-COV

HIV-2

HCV, HIV, IAV, and VACV

Viral E3 protein interacts with human and mouse ISG15

complex IFN-stimulated gene factor 3 (ISGF3)

NS4b proteins cause enzymatic degradation of OAS-RNase L

Antagonize tetherin by interacting with viral Rod envelope glycoprotein

E2/NS5A, Tat, NS1, and E3I/K3L viral proteins of respective viruses interact with PKR
Gonzalez-Mariscal et al., 2009

Garcia et al., 2017

Keele and Estes, 2011

Grünvogel et al., 2018

Li et al., 2016

Ramanan et al., 2012

Verrier et al., 2018

Chang et al., 1992; Hatada

and Fukuda, 1992

Feng et al., 2014; Lind

et al., 2016

Abe et al., 2007

Stack et al., 2005

Liu et al., 2020

Lui et al., 2016; Lee et al., 2019

Wang et al., 2000

Karim et al., 2013

Macdonald et al., 2003

Smith et al., 2013

Lei et al., 2013

Siu et al., 2009

Basler et al., 2003

Ronco et al., 1998

Li et al., 1999

Ulane et al., 2003

Yokota et al., 2004

Oda et al., 2017

Morrison et al., 2013; Grant et al., 2016

Wu et al., 2017

Shabman et al., 2011

Sen et al., 2014

Sugai et al., 2017

Schomacker et al., 2017

Wang et al., 2019

Eduardo-Correia et al., 2014

Thornbrough et al., 2016

Le Tortorec and Neil, 2009

Reviewed in Short, 2009 


\section{Inactivation of Transcriptional Factors}

At the basal level, transcriptional factors are inactive. After viral infection, transcriptional factors, such as IRF3/5/7, NF-kB, AP1, and others translocate into the nucleus and then induce the robust expression of IFNs (Christensen and Thomsen, 2009; Iwasaki and Pillai, 2014; Chen et al., 2018). Several conserved viral proteins, predominantly non-structural (NS) proteins, are extensively reported to exert potent antagonistic effects of IFN responses by several mechanisms. Viruses are reported to inhibit IFN induction by inducing degradation transcription factors, inhibiting their activation by blocking downstream signaling of PRRs, sequestering them, impeding their nuclear translocation, or inhibiting their binding to promoters of downstream antiviral genes, and so forth (Table 1). For example, IAV NS1 protein, extensively characterized as a potent antagonist of IFN-signaling, inhibits activation and nuclear translocation of IRF3 and NF- $\mathrm{kB}$ (Wang et al., 2000). Human cytomegalovirus (HCMV) is wellknown for establishing long-term latent infections. The innate immune escape strategy of HCMV is appeared to be pivotal for establishing such infections. UL44 protein of HCMV decelerates antiviral responses by inhibiting the binding of IRF3 and NF- $\kappa B$ to the promoters of downstream antiviral genes (Fu et al., 2019).

\section{Regulating the Transcriptional and Translation of Key Elements of Innate Immunity}

Transcription and translation of key elements of antiviral innate immunity, such as PRRs, IRFs, IFNs, STATs, ISGs, and others are very important for eliciting an antiviral response. Cumulative reports suggest that viruses can deregulate the transcription and translation of such elements. Caliciviridae, Coronaviridae, Picornaviridae, Orthomyxoviridae, Reoviridae, and many others exploit multiple tactics to induce host translational shut-off and thus prevent the infected cells from synthesizing new peptides and proteins, including those IFN-stimulated IRFs and STATs (reviewed in Chiang and Liu, 2019). HIV-1 Vpu protein potently suppresses NF-kB-elicited antiviral immune responses at the transcriptional level (Langer et al., 2019). Epstein-Barr virus BRLF1 inhibits the transcription of IRF3 and IRF7 (Bentz et al., 2010). IAV induces rapid degradation of eukaryotic translation initiation factor 4B (an integral component of the translation initiation apparatus) and contributes to viral replication at least by suppressing IFITM3 protein expression (Wang et al., 2014).

\section{Antagonizing IFN Induced JAK-STAT Signaling}

Besides the aforementioned viral escape strategies, viruses have evolved strategies to antagonize IFN and its downstream signaling through numerous sophisticated mechanisms. Mechanisms include targeting degradation of IFNs receptors, retention of suppression of STATs in the cytoplasm, inhibition of STAT activation, degradation of STATs through the proteasome, and so forth. NS4B protein of several flaviviruses inhibits IFN signaling-induced JAK-STAT signaling in a multitude of ways (Munoz-Jordán et al., 2005). Flavivirus NS5 protein dysregulates HSP90 to inhibit JAK/STAT signaling (Roby et al., 2020). NS2A,
NS2B, NS3, NS4A, and NS4B proteins of WNV block STAT1 and STAT2 activation (Liu et al., 2005). 2A proteinase of Enterovirus 71 degrades IFNAR1 (Lu et al., 2012). HCV and flaviviruses hijack cellular mechanisms for nuclear STAT2 degradation by up-regulation of PDLIM2 (Joyce et al., 2019). Nsp5 protein of porcine deltacoronavirus, an emerging coronavirus, cleaves STAT2 (Zhu et al., 2017). Orf6 of SARS-CoV-2 hijacks Nup98 to block STAT nuclear import (Miorin et al., 2020). There is a range of literature regarding the viral invasion of innate immunity by antagonizing IFN and IFN induced downstream signaling (Liu et al., 2005, 2020; Lu et al., 2012; Chan and Gack, 2016; Scott and Nel, 2016; Zhu et al., 2017; Maarouf et al., 2018; Joyce et al., 2019; Acharya et al., 2020; Miorin et al., 2020).

\section{Viral Invasion of ISGs}

Global ISG response plays a very important role in viral clearance. Delayed ISG production is advantageous for viral replication and spread into host tissues. Viruses also exploit several distinct approaches to antagonize the global ISG response (Short, 2009). Highly pathogenic influenza viruses and coronaviruses induce repressive histone modifications, which downregulates the global expression of ISG subsets (Menachery et al., 2014). Although interferon-induced transmembrane proteins (IFITMs) play an antiviral role against a large group of viruses, particularly during viral invasion to the host at entry stage, human cytomegalovirus can exploit IFITM proteins to facilitate morphogenesis of the virion assembly compartment (Xie et al., 2015). Viral invasion of ISGs has been extensively reviewed elsewhere (Table 1; Kanodia et al., 2007; Short, 2009; Su et al., 2016).

\section{Regulating Autophagy}

Autophagy, an autonomous arm of innate immunity, is a cytosolic lysosome-dependent catabolic process that mediates viral clearance. Autophagy can be upregulated upon virus detection by pathogen receptors, including membranebound and cytosolic PRRs, and which may further facilitate PRR-dependent signaling and also contribute induction of type I IFNs (Richetta and Faure, 2013). Beclin-1 is an essential macro-autophagy protein that constitutes part of the phosphatidylinositol-3 kinase complexes that mark membranes for autophagosome generation and facilitate autophagosome fusion with lysosomes (Münz, 2011). $\alpha$-herpesvirus Akt-like Ser/Thr kinase limits autophagy to stimulate virus replication by inhibition of ULK1 and Beclin1 (Rubio and Mohr, 2019). Pseudorabies virus infection inhibits autophagy in permissive cells in vitro (Sun et al., 2017). Viral proteins ICP34.5, orf16, and M11 of viruses HSV-1, KSHV, and MHV-68, respectively, block autophagosome generation, whereas nef and M2 viral proteins of HIV and IAV, respectively, inhibit autophagosome maturation (Choi et al., 2018). Readers can also refer to some previously published review papers (Münz, 2011; Richetta and Faure, 2013; Jackson, 2015; Lennemann and Coyne, 2015; Sun et al., 2017; Choi et al., 2018; Rubio and Mohr, 2019).

\section{Other Mechanisms}

In addition to the aforementioned viral immune escape mechanisms, a large group of viruses often encode proteins 
to inactivate released cytokines or chemokines by binding, solubilizing, and altering the cellular responsiveness (Lucas et al., 2001). Numerous viruses including HIV-1, HCV, HBV, HSV-1, RSV, EBOV, IAV, and others induce robust expression of suppressors of cytokine signaling (SOCS) proteins (Akhtar and Benveniste, 2011). SOCS proteins induced by cytokine signaling during viral infection function as negative feedback regulators to reduce inflammation and promote viral replication (Akhtar and Benveniste, 2011). More interestingly, some viruses can directly induce SOCS proteins independently of cytokine signaling. For example, the influenza virus induces the expression of SOCS3 in a cytokine-independent manner to circumvent IL6/STAT3-mediated immune response (Liu et al., 2019). Virusinduced stress granules, the cytoplasmic dense aggregates of proteins and RNAs produced when cells are in stress, can also play an important role in innate immunity by recruiting viral sensors, such as RIG-I, MDA5, PKR, and so forth to initiate downstream antiviral innate immune signaling (McCormick and Khaperskyy, 2017). Several viruses brilliantly inhibit such stress granule formation by diverse mechanisms (Wu et al., 2014; McCormick and Khaperskyy, 2017). Moreover, viruses can also circumvent antiviral immunity through sequestering critical elements of innate immunity, such as TBK1, IKKE, and IRF3 into viral inclusion bodies (Wu et al., 2014). Other famous escape mechanisms include hijacking transcriptional and translational machineries for their survival, which can also mediate the circumvention of innate immune response in multiple ways. For example, the Nsp1 protein of SARS-CoV-2 mediates host translation shutdown and evades innate immunity (Thoms et al., 2020).

\section{PERSPECTIVES AND CONCLUSION}

Obstructing viral immune invasion could potentially provide an alternative approach for the prevention and treatment of disease caused by an acute infection of viral pathogens. Increasing data regarding viral innate immune escape mechanisms have been reported. However, most of these data are limited to in vitro (cell culture system) and in vivo animal models. The relevance of viral escape mechanisms identified by these models may not apply the same in human. Therefore, this issue remains to be addressed by extensive ex vivo experiments in the human model. The molecular basis of antiviral innate immune signaling is complex, multi-waved, inter-connected, and may not always be antiviral. For instance, it is well-known that TLR signals induce robust expression of antiviral innate immunity for viral clearance. However, in certain circumstances, the activation of particular TLR responses by pathogens might serve as an escape mechanism from the host defense (Netea et al., 2004). Furthermore, studies for the in-depth understanding of virushost interaction are very important because the molecular basis of viral escape mechanisms and crosstalk among immune signaling for the progression of disease are still largely unexplored.
Of several conserved viral proteins, predominantly NS proteins appear to be major antagonists of the elements of innate immunity. Since viral NS proteins play a vital role in innate immune escape mechanisms, there is a pressing need for scientists to uncover host factors countering those viral NS proteins. Supportively, recent reports have arguably characterized host factors countering such viral proteins. For instances, virus-induced TRIM22, viperin, and p27Kip1 mediate rapid degradation of HCV NS5A, ZIKA NS, and IAV NS1 proteins, respectively (Yang et al., 2016; Panayiotou et al., 2018; Rai et al., 2020). Identification and characterization of such types of host factors countering these viral proteins in the future are truly indispensable in elaborating antiviral innate immunity.

A virus may exploit numerous and multiple immune escape tactics collectively and cooperatively for effective immune evasion. However, most of the previously published experimental data are mostly limited to viral escape tactics specifically at the individual level. Comprehensive studies on how viruses exploit their overall immune escape tactics together for disease progression or host killing in acute viral infection or in establishing successful infection should have been experimentally substantiated. Moreover, the consequences of cytokine storms in acute viral infection have been widely studied but the mechanistic basis of differential cytokine storm production and why the magnitude of cytokine storm production differs from one individual to another are largely unknown.

In conclusion, an acute viral infection can cause sudden or rapid onset of disease that may be resolved quickly or may be fatal. Innate immunity provides the first line of defense for viral clearance. However, viruses have evolved strategies to escape the host's antiviral innate immune surveillance that may kill the host or establish persistent infections. There are still many unanswered questions regarding the impact of viral escape strategies on host killing and viral persistence. Comprehensive understanding of the underlying complex molecular basis of viral escapology would help provide landmark achievements in our ongoing battle against viral infections.

\section{AUTHOR CONTRIBUTIONS}

KR, PS, BY, YC, SL, and MM performed a systematic literature review. KR wrote the manuscript. J-LC organized and critically revised the manuscript. BY helped in the manuscript revision and drawing figure. All authors have read and agreed to the published version of the manuscript.

\section{FUNDING}

This work was supported by the National Science Foundation of China (U1805231 and 32030110) and the National Key Research and Development Program of China (2016YFD0500205). 


\section{REFERENCES}

Abe, T., Kaname, Y., Hamamoto, I., Tsuda, Y., Wen, X., Taguwa, S., et al. (2007). Hepatitis $\mathrm{C}$ virus nonstructural protein $5 \mathrm{~A}$ modulates the toll-like receptorMyD88-dependent signaling pathway in macrophage cell lines. J. Virol. 81, 8953-8966. doi: 10.1128/jvi.00649-07

Acharya, D., Liu, G., and Gack, M. U. (2020). Dysregulation of type I interferon responses in COVID-19. Nat. Rev. Immunol. 20, 397-398. doi: 10.1038/s41577020-0346-x

Akhtar, L. N., and Benveniste, E. N. (2011). Viral exploitation of host SOCS protein functions. J. Virol. 85, 1912-1921. doi: 10.1128/jvi.01857-10

Ascenzi, P., Bocedi, A., Heptonstall, J., Capobianchi, M. R., Di Caro, A., Mastrangelo, E., et al. (2008). Ebolavirus and Marburgvirus: insight the Filoviridae family. Mol. Aspects Med. 29, 151-185. doi: 10.1016/j.mam.2007.09. 005

Basler, C. F., Mikulasova, A., Martinez-Sobrido, L., Paragas, J., Mühlberger, E., Bray, M., et al. (2003). The Ebola virus VP35 protein inhibits activation of interferon regulatory factor 3. J. Virol. 77, 7945-7956. doi: 10.1128/JVI.77.14.7945-7956. 2003

Bentz, G. L., Liu, R., Hahn, A. M., Shackelford, J., and Pagano, J. S. (2010). EpsteinBarr virus BRLF1 inhibits transcription of IRF3 and IRF7 and suppresses induction of interferon- $\beta$. Virology 402, 121-128. doi: 10.1016/j.virol.2010.03. 014

Blanco-Melo, D., Nilsson-Payant, B. E., Liu, W. C., Uhl, S., Hoagland, D., Møller, R., et al. (2020). Imbalanced host response to SARS-CoV-2 drives development of COVID-19. Cell 181, 1036-1045.e9. doi: 10.1016/j.cell.2020.04.026

Bowie, A. G., and Unterholzner, L. (2008). Viral evasion and subversion of patternrecognition receptor signalling. Nat. Rev. Immunol. 8, 911-922. doi: 10.1038/ nri2436

Centre for Disease Control and Prevention (CDC) (2012). Influenza (Flu), First Global Estimates of 2009 H1N1 Pandemic Mortality Released by CDCLed Collaboration. Available online at: https://www.cdc.gov/flu/spotlights/ pandemic-global-estimates.htm (accessed on October 19, 2020).

Chan, Y. K., and Gack, M. U. (2016). Viral evasion of intracellular DNA and RNA sensing. Nat. Rev. Microbiol. 14, 360-373. doi: 10.1038/nrmicro.2016.45

Chang, H. W., Watson, J. C., and Jacobs, B. L. (1992). The E3L gene of vaccinia virus encodes an inhibitor of the interferon-induced, double-stranded RNAdependent protein kinase. Proc. Natl. Acad. Sci. U.S.A. 89, 4825-4829. doi: 10.1073/pnas.89.11.4825

Chauhan, R. P., Dessie, Z. G., Noreddin, A., and El Zowalaty, M. E. (2020). Systematic review of important viral diseases in africa in light of the 'One health'concept. Pathogens 9:301. doi: 10.3390/pathogens9040301

Chen, S., Wu, Z., Wang, M., and Cheng, A. (2017). Innate immune evasion mediated by flaviviridae non-structural proteins. Viruses 9:291. doi: 10.3390/ v9100291

Chen, X., Liu, S., Goraya, M. U., Maarouf, M., Huang, S., and Chen, J. L. (2018). Host immune response to influenza a virus infection. Front. Immunol. 9:320. doi: 10.3389/fimmu.2018.00320

Chiang, C., Pauli, E. K., Biryukov, J., Feister, K. F., Meng, M., White, E. A., et al. (2018). The human papillomavirus E6 oncoprotein targets USP15 and TRIM25 to suppress RIG-I-mediated innate immune signaling. J. Virol. 92:e01737-17. doi: 10.1128/jvi.01737-17

Chiang, H. S., and Liu, H. M. (2019). The molecular basis of viral inhibition of IRF-and STAT-dependent immune responses. Front. Immunol. 9:3086. doi: 10.3389/fimmu.2018.03086

Choi, Y., Bowman, J. W., and Jung, J. U. (2018). Autophagy during viral infectiona double-edged sword. Nat. Rev. Microbiol. 16, 341-354. doi: 10.1038/s41579018-0003-6

Christensen, J. E., and Thomsen, A. R. (2009). Co-ordinating innate and adaptive immunity to viral infection: mobility is the key. APMIS 117, 338-355. doi: 10.1111/j.1600-0463.2009.02451.x

Doran, K. S., Banerjee, A., Disson, O., and Lecuit, M. (2013). Concepts and mechanisms: crossing host barriers. Cold Spring Harb. Perspect. Med. 3:a010090. doi: 10.1101/cshperspect.a010090

Eduardo-Correia, B., Martínez-Romero, C., García-Sastre, A., and Guerra, S. (2014). ISG15 is counteracted by vaccinia virus E3 protein and controls the proinflammatory response against viral infection. J. Virol. 88, 2312-2318. doi: 10.1128/JVI.03293-13
Encinar, J. A., and Menendez, J. A. (2020). Potential drugs targeting early innate immune evasion of sars-coronavirus 2 via 2'-O-methylation of viral RNA. Viruses 12:525. doi: 10.3390/v12050525

Felsenstein, S., Herbert, J. A., McNamara, P. S., and Hedrich, C. M. (2020). COVID19: immunology and treatment options. Clin. Immunol. 27:108448. doi: 10. 1016/j.clim.2020.108448

Feng, Q., Langereis, M. A., Lork, M., Nguyen, M., Hato, S. V., Lanke, K., et al. (2014). Enterovirus 2Apro targets MDA5 and MAVS in infected cells. J. Virol. 88, 3369-3378. doi: 10.1128/jvi.02712-13

Fensterl, V., and Sen, G. C. (2009). Interferons and viral infections. Biofactors 35, 14-20. doi: 10.1002/biof.6

Foster, T. L., Wilson, H., Iyer, S. S., Coss, K., Doores, K., Smith, S., et al. (2016). Resistance of transmitted founder HIV-1 to IFITM-mediated restriction. Cell Host Microbe 20, 429-442. doi: 10.1016/j.chom.2016.08.006

Fu, Y. Z., Su, S., Zou, H. M., Guo, Y., Wang, S. Y., Li, S., et al. (2019). Human cytomegalovirus DNA polymerase subunit UL44 antagonizes antiviral immune responses by suppressing IRF3-and NF- $\mathrm{BB}-$ mediated transcription. J. Virol. 93:e00181-19. doi: 10.1128/JVI.00181-19

Garcia, M., Wehbe, M., Lévêque, N., and Bodet, C. (2017). Skin innate immune response to flaviviral infection. Eur. Cytokine Netw. 28, 41-51. doi: 10.1684/ecn. 2017.0394

Gerges Harb, J., Noureldine, H. A., Chedid, G., Eldine, M. N., Abdallah, D. A., Chedid, N. F., et al. (2020). SARS, MERS and COVID-19: clinical manifestations and organ-system complications: a mini review. Pathog. Dis. 78:ftaa033. doi: 10.1093/femspd/ftaa033

Gerold, G., Moeller, R., and Pietschmann, T. (2020). Hepatitis C virus entry: protein interactions and fusion determinants governing productive hepatocyte invasion. Cold Spring Harb. Perspect. Med. 10:a036830. doi: 10.1101/ cshperspect.a036830

Gonzalez-Mariscal, L., Garay, E., and Lechuga, S. (2009). Virus interaction with the apical junctional complex. Front. Biosci. 14:731-768. doi: 10.2741/3276

Goraya, M. U., Wang, S., Munir, M., and Chen, J. L. (2015). Induction of innate immunity and its perturbation by influenza viruses. Protein Cell 6, 712-721. doi: $10.1007 /$ s13238-015-0191-z

Goubau, D., Deddouche, S., and Reis e Sousa, C. (2013). Cytosolic sensing of viruses. Immunity 38, 855-869. doi: 10.1016/j.immuni.2013.05.007

Gould, E. A., and Solomon, T. (2008). Pathogenic flaviviruses. Lancet 371, 500-509. doi: 10.1016/S0140-6736(08)60238-X

Grant, A., Ponia, S. S., Tripathi, S., Balasubramaniam, V., Miorin, L., Sourisseau, M., et al. (2016). Zika Virus targets human STAT2 to inhibit type I interferon signaling. Cell Host Microbe 19, 882-890. doi: 10.1016/j.chom.2016.05.009

Grünvogel, O., Colasanti, O., Lee, J. Y., Klöss, V., Belouzard, S., Reustle, A., et al. (2018). Secretion of hepatitis $C$ virus replication intermediates reduces activation of toll-like receptor 3 in hepatocytes. Gastroenterology 154, 22372251.e16. doi: 10.1053/j.gastro.2018.03.020

Guo, D. (2020). Old weapon for new enemy: drug repurposing for treatment of newly emerging viral diseases. Virol. Sin. 35, 253-255. doi: 10.1007/s12250020-00204-7

Hatada, E., and Fukuda, R. (1992). Binding of influenza a virus NS1 protein to dsRNA in vitro. J. Gen. Virol. 73(Pt 12), 3325-3329. doi: 10.1099/0022-131773-12-3325

Heim, M. H., and Thimme, R. (2014). Innate and adaptive immune responses in HCV infections. J. Hepatol. 61, S14-S25. doi: 10.1016/j.jhep.2014.06.035

Herrington, C. S., Coates, P. J., and Duprex, W. P. (2015). Viruses and disease: emerging concepts for prevention, diagnosis and treatment. J. Pathol. 235, 149-152. doi: 10.1002/path.4476

Ishikawa, H., Ma, Z., and Barber, G. N. (2009). STING regulates intracellular DNAmediated, type I interferon-dependent innate immunity. Nature 461, 788-792. doi: 10.1038/nature08476

Iwasaki, A., and Pillai, P. S. (2014). Innate immunity to influenza virus infection. Nat. Rev. Immunol. 14, 315-328. doi: 10.1038/nri3665

Jackson, W. T. (2015). Viruses and the autophagy pathway. Virology 479, 450-456. doi: 10.1016/j.virol.2015.03.042

Jacob, S. T., Crozier, I., Fischer, W. A., Hewlett, A., Kraft, C. S., de La Vega, M. A., et al. (2020). Ebola virus disease. Nat. rev. Dis. Primers 6:31. doi: 10.1038/ s41572-020-0147-3

Jensen, S., and Thomsen, A. R. (2012). Sensing of RNA viruses. J. Virol. 86, 2900-2910. doi: 10.1128/JVI.05738-11 
Joyce, M. A., Berry-Wynne, K. M., Dos Santos, T., Addison, W. R., McFarlane, N., Hobman, T., et al. (2019). HCV and flaviviruses hijack cellular mechanisms for nuclear STAT2 degradation: up-regulation of PDLIM2 suppresses the innate immune response. PLoS Pathogens 15:e1007949. doi: 10.1371/journal.ppat. 1007949

Kanodia, S., Fahey, L. M., and Kast, W. M. (2007). Mechanisms used by human papillomaviruses to escape the host immune response. Curr. Cancer Drug Targets 7, 79-89. doi: 10.2174/156800907780006869

Karim, R., Tummers, B., Meyers, C., Biryukov, J. L., Alam, S., Backendorf, C., et al. (2013). Human papillomavirus (HPV) upregulates the cellular deubiquitinase UCHL1 to suppress the keratinocyte's innate immune response. PLoS Pathog. 9:e1003384. doi: 10.1371/journal.ppat.1003384

Kawai, T., and Akira, S. (2010). The role of pattern-recognition receptors in innate immunity: update on Toll-like receptors. Nat. Immunol. 11:373. doi: 10.1038/ ni. 1863

Keele, B. F., and Estes, J. D. (2011). Barriers to mucosal transmission of immunodeficiency viruses. Blood 118, 839-846. doi: 10.1182/blood-2010-12325860

Keighley, C. L., Saunderson, R. B., Kok, J., and Dwyer, D. E. (2015). Viral exanthems. Curr. Opin. Infect. Dis. 28, 139-150. doi: 10.1097/QCO. 0000000000000145

Kikkert, M. (2020). Innate immune evasion by human respiratory RNA viruses. J. Innate Immun. 12, 4-20. doi: 10.1159/000503030

Koyama, S., Ishii, K. J., Coban, C., and Akira, S. (2008). Innate immune response to viral infection. Cytokine 43, 336-341. doi: 10.1016/j.cyto.2008.07.009

Langer, S., Hammer, C., Hopfensperger, K., Klein, L., Hotter, D., De Jesus, P. D., et al. (2019). HIV-1 Vpu is a potent transcriptional suppressor of NF-KB-elicited antiviral immune responses. Elife 8:e41930. doi: 10.7554/eLife.41930

Lazear, H. M., Lancaster, A., Wilkins, C., Suthar, M. S., Huang, A., Vick, S. C., et al. (2013). IRF-3, IRF-5, and IRF-7 coordinately regulate the type I IFN response in myeloid dendritic cells downstream of MAVS signaling. PLoS Pathog. 9:e1003118. doi: 10.1371/journal.ppat.1003118

Le Tortorec, A., and Neil, S. J. (2009). Antagonism to and intracellular sequestration of human tetherin by the human immunodeficiency virus type 2 envelope glycoprotein. J. Virol. 83, 11966-11978. doi: 10.1128/JVI.01 515-09

Lee, J. Y., Bae, S., and Myoung, J. (2019). Middle east respiratory syndrome coronavirus-encoded accessory proteins impair MDA5-and TBK1-mediated activation of NF-кB. J. Microbiol. Biotechnol. 29, 1316-1323. doi: 10.4014/jmb. 1908.08004

Lei, X., Xiao, X., Xue, Q., Jin, Q., He, B., and Wang, J. (2013). Cleavage of interferon regulatory factor 7 by enterovirus $713 \mathrm{C}$ suppresses cellular responses. J. Virol. 87, 1690-1698. doi: 10.1128/jvi.01855-12

Lennemann, N. J., and Coyne, C. B. (2015). Catch me if you can: the link between autophagy and viruses. PLoS Pathog. 11:e1004685. doi: 10.1371/journal.ppat. 1004685

Lhomme, S., Migueres, M., Abravanel, F., Marion, O., Kamar, N., and Izopet, J. (2020). Hepatitis E virus: how it escapes host innate immunity. Vaccines 8:422. doi: $10.3390 /$ vaccines 8030422

Li, F., Chen, Y., Zhang, Z., Ouyang, J., Wang, Y., Yan, R., et al. (2015). Robust expression of vault RNAs induced by influenza A virus plays a critical role in suppression of PKR-mediated innate immunity. Nucleic Acids Res. 43, 1032110337. doi: 10.1093/nar/gkv1078

Li, S., Labrecque, S., Gauzzi, M. C., Cuddihy, A. R., Wong, A. H., Pellegrini, S., et al. (1999). The human papilloma virus (HPV)-18 E6 oncoprotein physically associates with Tyk2 and impairs Jak-STAT activation by interferon-alpha. Oncogene 18, 5727-5737. doi: 10.1038/sj.onc. 1202960

Li, S. W., Wang, C. Y., Jou, Y. J., Huang, S. H., Hsiao, L. H., Wan, L., et al. (2016). SARS coronavirus papain-like protease inhibits the TLR7 signaling pathway through removing Lys63-linked polyubiquitination of TRAF3 and TRAF6. Int. J. Mol. Sci. 17:678. doi: 10.3390/ijms17050678

Li, W., Li, N., Dai, S., Hou, G., Guo, K., Chen, X., et al. (2019). Zika virus circumvents host innate immunity by targeting the adaptor proteins MAVS and MITA. FASEB J. 33, 9929-9944. doi: 10.1096/fj.201900260R

Lind, K., Svedin, E., Domsgen, E., Kapell, S., Laitinen, O. H., Moll, M., et al. (2016). Coxsackievirus counters the host innate immune response by blocking type III interferon expression. J. Gen. Virol. 97, 1368-1380. doi: 10.1099/jgv.0.000443
Liu, P., Hong, Y., Yang, B., Shrestha, P., Sajjad, N., and Chen, J. L. (2020). Induction of the antiviral immune response and its circumvention by coronaviruses. Viruses 12:1039. doi: 10.3390/v12091039

Liu, Q., Zhou, Y. H., and Yang, Z. Q. (2016). The cytokine storm of severe influenza and development of immunomodulatory therapy. Cell. Mol. Immunol. 13, 3-10. doi: $10.1038 / \mathrm{cmi} .2015 .74$

Liu, S., Liao, Y., Chen, B., Chen, Y., Yu, Z., Wei, H., et al. (2021). Critical role of Sykdependent STAT1 activation in innate antiviral immunity. Cell Rep. 34:108627. doi: 10.1016/j.celrep.2020.108627

Liu, S., Yan, R., Chen, B., Pan, Q., Chen, Y., Hong, J., et al. (2019). Influenza virusinduced robust expression of SOCS3 contributes to excessive production of IL-6. Front. Immunol. 10:1843. doi: 10.3389/fimmu.2019.01843

Liu, W. J., Wang, X. J., Mokhonov, V. V., Shi, P. Y., Randall, R., and Khromykh, A. A. (2005). Inhibition of interferon signaling by the New York 99 strain and Kunjin subtype of West Nile virus involves blockage of STAT1 and STAT2 activation by nonstructural proteins. J. Virol. 79, 1934-1942. doi: 10.1128/jvi. 79.3.1934-1942.2005

Long, J. S., Mistry, B., Haslam, S. M., and Barclay, W. S. (2019). Host and viral determinants of influenza A virus species specificity. Nat. Rev. Microbiol. 17, 67-81. doi: 10.1038/s41579-018-0115-Z

Lu, J., Yi, L., Zhao, J., Yu, J., Chen, Y., Lin, M. C., et al. (2012). Enterovirus 71 disrupts interferon signaling by reducing the level of interferon receptor 1 . J. Virol. 86, 3767-3776. doi: 10.1128/JVI.06687-11

Lucas, M., Karrer, U. R., Lucas, A., and Klenerman, P. (2001). Viral escape mechanisms-escapology taught by viruses. Int. J. Exp. Pathol. 82, 269-286. doi: $10.1046 / j .1365-2613.2001 .00204 . x$

Lui, P. Y., Wong, L. Y., Fung, C. L., Siu, K. L., Yeung, M. L., Yuen, K. S., et al. (2016). Middle East respiratory syndrome coronavirus M protein suppresses type I interferon expression through the inhibition of TBK1-dependent phosphorylation of IRF3. Emerg. Microbes Infect. 5:e39. doi: 10.1038/emi. 2016.33

Ma, Z., Ni, G., and Damania, B. (2018). Innate sensing of DNA virus genomes. Annu. Rev. Virol. 5, 341-362. doi: 10.1146/annurev-virology-092917-043244

Maarouf, M., Rai, K. R., Goraya, M. U., and Chen, J. L. (2018). Immune ecosystem of virus-infected host tissues. Int. J. Mol. Sci. 19:1379. doi: 10.3390/ ijms 19051379

Macdonald, A., Crowder, K., Street, A., McCormick, C., Saksela, K., and Harris, M. (2003). The hepatitis C virus non-structural NS5A protein inhibits activating protein-1 function by perturbing ras-ERK pathway signaling. J. Biol. Chem. 278, 17775-17784. doi: 10.1074/jbc.M210900200

MacLachlan, N., and Dubovi, E. (Eds) (2017). "Pathogenesis of viral infections and diseases," in Fenner's Veterinary Virology, 5th Edn. (New York, NY: Academic Press), 47-78. doi: 10.1016/B978-0-12-800946-8.00003-9

Mahmudpour, M., Roozbeh, J., Keshavarz, M., Farrokhi, S., and Nabipour, I. (2020). COVID-19 cytokine storm: the anger of inflammation. Cytokine 133:155151. doi: 10.1016/j.cyto.2020.155151

Majoros, A., Platanitis, E., Kernbauer-Hölzl, E., Rosebrock, F., Müller, M., and Decker, T. (2017). Canonical and non-canonical aspects of JAK-STAT signaling: lessons from interferons for cytokine responses. Front. Immunol. 8:29. doi: $10.3389 /$ fimmu. 2017.00029

Marc, D. (2014). Influenza virus non-structural protein NS1: interferon antagonism and beyond. J. Gen. Virol. 95, 2594-2611. doi: 10.1099/vir.0. 069542-0

McCormick, C., and Khaperskyy, D. A. (2017). Translation inhibition and stress granules in the antiviral immune response. Nat. Rev. Immunol. 17:647. doi: 10.1038/nri.2017.63

Menachery, V. D., Eisfeld, A. J., Schäfer, A., Josset, L., Sims, A. C., Proll, S., et al. (2014). Pathogenic influenza viruses and coronaviruses utilize similar and contrasting approaches to control interferon-stimulated gene responses. mBio 5:e01174-14. doi: 10.1128/mBio.01174- 14

Miorin, L., Kehrer, T., Sanchez-Aparicio, M. T., Zhang, K., Cohen, P., Patel, R. S., et al. (2020). SARS-CoV-2 Orf6 hijacks Nup98 to block STAT nuclear import and antagonize interferon signaling. Proc. Natl. Acad. Sci. U.S.A. 117, 28344-28354. doi: 10.1073/pnas.2016650117

Morgan Brisse, H. L. (2019). Comparative structure and function analysis of the RIG-I-like receptors: RIG-I and MDA5. Front. Immunol. 10:1586. doi: 10.3389/ fimmu.2019.01586 
Morrison, J., Laurent-Rolle, M., Maestre, A. M., Rajsbaum, R., Pisanelli, G., Simon, V., et al. (2013). Dengue virus co-opts UBR4 to degrade STAT2 and antagonize type I interferon signaling. PLoS Pathog. 9:e1003265. doi: 10.1371/journal.ppat. 1003265

Mukherjee, A., Morosky, S. A., Delorme-Axford, E., Dybdahl-Sissoko, N., Oberste, M. S., Wang, T., et al. (2011). The coxsackievirus B 3Cpro protease cleaves MAVS and TRIF to attenuate host type I interferon and apoptotic signaling. PLoS Pathog. 7:e1001311. doi: 10.1371/journal.ppat.1001311

Munoz-Jordán, J. L., Laurent-Rolle, M., Ashour, J., Martínez-Sobrido, L., Ashok, M., Lipkin, W. I., et al. (2005). Inhibition of alpha/beta interferon signaling by the NS4B protein of flaviviruses. J. Virol. 79, 8004-8013. doi: 10.1128/jvi.79.13. 8004-8013.2005

Münz, C. (2011). Beclin-1 targeting for viral immune escape. Viruses 3, 1166-1178. doi: $10.3390 / \mathrm{v} 3071166$

Netea, M. G., Van der Meer, J. W., and Kullberg, B. J. (2004). Toll-like receptors as an escape mechanism from the host defense. Trends Microbiol. 12, 484-488. doi: 10.1016/j.tim.2004.09.004

Newton, A. H., Cardani, A., and Braciale, T. J. (2016). The host immune response in respiratory virus infection: balancing virus clearance and immunopathology. Semin. Immunopathol. 38, 471-482. doi: 10.1007/s00281-016-0558-0

Oda, K., Oda, T., Matoba, Y., Sato, M., Irie, T., and Sakaguchi, T. (2017). Structural analysis of the STAT1:STAT2 heterodimer revealed the mechanism of Sendai virus C protein-mediated blockade of type 1 interferon signaling. J. Biol. Chem. 292, 19752-19766. doi: 10.1074/jbc.M117.786285

Osburn, W. O., Levine, J. S., Chattergoon, M. A., Thomas, D. L., and Cox, A. L. (2013). Anti-inflammatory cytokines, pro-fibrogenic chemokines and persistence of acute HCV infection. J. Viral Hepat. 20, 404-413. doi: 10.1111/ jvh.12052

Panayiotou, C., Lindqvist, R., Kurhade, C., Vonderstein, K., Pasto, J., Edlund, K., et al. (2018). Viperin restricts Zika virus and tick-borne encephalitis virus replication by targeting NS3 for proteasomal degradation. J. Virol. 92:e205417. doi: 10.1128/jvi.02054-17

Paul, A., Tang, T. H., and Ng, S. K. (2018). Interferon regulatory factor 9 structure and regulation. Front. Immunol. 9:1831. doi: 10.3389/fimmu.2018.01831

Qi, H., Chu, V., Wu, N. C., Chen, Z., Truong, S., Brar, G., et al. (2017). Systematic identification of anti-interferon function on hepatitis $\mathrm{C}$ virus genome reveals p7 as an immune evasion protein. Proc. Natl. Acad. Sci. 114, 2018-2023. doi: $10.1073 /$ pnas.1614623114

Rai, K. R., Chen, B., Zhao, Z., Chen, Y., Hu, J., Liu, S., et al. (2020). Robust expression of p27Kip1 induced by viral infection is critical for antiviral innate immunity. Cell. Microbiol. 22:e13242. doi: 10.1111/cmi.13242

Ramanan, P., Edwards, M. R., Shabman, R. S., Leung, D. W., Endlich-Frazier, A. C., Borek, D. M., et al. (2012). Structural basis for Marburg virus VP35-mediated immune evasion mechanisms. Proc. Natl. Acad. Sci. U.S.A. 109, 20661-20666. doi: $10.1073 /$ pnas. 1213559109

Ramos-Casals, M., Cuadrado, M. J., Alba, P., Sanna, G., Brito-Zerón, P., Bertolaccini, L., et al. (2008). Acute viral infections in patients with systemic lupus erythematosus: description of 23 cases and review of the literature. Medicine 87, 311-318. doi: 10.1097/MD.0b013e31818ec711

Rathinam, V. A., and Fitzgerald, K. A. (2011). Innate immune sensing of DNA viruses. Virology 411, 153-162. doi: 10.1016/j.virol.2011.02.003

Richetta, C., and Faure, M. (2013). Autophagy in antiviral innate immunity. Cell. Microbiol. 15, 368-376. doi: 10.1111/cmi.12043

Roby, J. A., Esser-Nobis, K., Dewey-Verstelle, E. C., Fairgrieve, M. R., Schwerk, J., Lu, A. Y., et al. (2020). Flavivirus nonstructural protein NS5 dysregulates HSP90 to broadly inhibit JAK/STAT signaling. Cells 9:899. doi: 10.3390/cells9040899

Rojek, J. M., and Kunz, S. (2008). Cell entry by human pathogenic arenaviruses. Cell. Microbiol. 10, 828-835. doi: 10.1586/eri.10.142

Ronco, L. V., Karpova, A. Y., Vidal, M., and Howley, P. M. (1998). Human papillomavirus $16 \mathrm{E} 6$ oncoprotein binds to interferon regulatory factor-3 and inhibits its transcriptional activity. Genes Dev. 12, 2061-2072. doi: 10.1101/gad. 12.13.2061

Rubio, R. M., and Mohr, I. (2019). Inhibition of ULK1 and Beclin1 by an $\alpha$-herpesvirus Akt-like Ser/Thr kinase limits autophagy to stimulate virus replication. Proc. Natl. Acad. Sci. 116, 26941-26950. doi: 10.1073/pnas. 1915139116

Salomon, R., and Webster, R. G. (2009). The influenza virus enigma. Cell 136, 402-410. doi: 10.1016/j.cell.2009.01.029
Sanders, C. J., Doherty, P. C., and Thomas, P. G. (2011). Respiratory epithelial cells in innate immunity to influenza virus infection. Cell Tissue Res. 343, 13-21. doi: $10.1007 /$ s00441-010-1043-z

Schoggins, J. W. (2014). Interferon-stimulated genes: roles in viral pathogenesis. Curr. Opin. Virol. 6, 40-46. doi: 10.1016/j.coviro.2014.03.006

Schomacker, H., Hebner, R. M., Boonyaratanakornkit, J., Surman, S., AmaroCarambot, E., Collins, P. L., et al. (2017). The C proteins of human parainfluenza virus type 1 block IFN signaling by binding and retaining Stat 1 in perinuclear aggregates at the late endosome. PLoS One 7:e28382. doi: 10.1371/ journal.pone.0028382

Scott, T. P., and Nel, L. H. (2016). Subversion of the immune response by rabies virus. Viruses 8:231. doi: 10.3390/v8080231

Sen, A., Rott, L., Phan, N., Mukherjee, G., and Greenberg, H. B. (2014). Rotavirus NSP1 protein inhibits interferon-mediated STAT1 activation. J. Virol. 88, 41-53. doi: 10.1128/JVI.01501-13

Shabman, R. S., Gulcicek, E. E., Stone, K. L., and Basler, C. F. (2011). The Ebola virus VP24 protein prevents hnRNP C1/C2 binding to karyopherin $\alpha 1$ and partially alters its nuclear import. J. Infect. Dis. 3(Suppl. 3), S904-S910. doi: 10.1093/infdis/jir323

Shen, M., Xiao, Y., and Rong, L. (2015). Modeling the effect of comprehensive interventions on Ebola virus transmission. Sci. Rep. 5:15818. doi: 10.1038/ srep 15818

Shin, E. C., Sung, P. S., and Park, S. H. (2016). Immune responses and immunopathology in acute and chronic viral hepatitis. Nat. Rev. Immunol. 16:509. doi: 10.1038/nri.2016.69

Short, J. A. (2009). Viral evasion of interferon stimulated genes. Biosci. Horiz. 2, 212-224. doi: 10.1093/biohorizons/hzp014

Shrivastava, G., León-Juárez, M., García-Cordero, J., Meza-Sánchez, D. E., and Cedillo-Barrón, L. (2016). Inflammasomes and its importance in viral infections. Immunol. Res. 64, 1101-1117. doi: 10.1007/s12026-016-8873-z

Shuaib, W., Stanazai, H., Abazid, A. G., and Mattar, A. A. (2016). Re-emergence of Zika virus: a review on pathogenesis, clinical manifestations, diagnosis, treatment, and prevention. Am. J. med. 129, 879.e7-879.e12. doi: 10.1016/j. amjmed.2016.02.027

Siu, K. L., Kok, K. H., Ng, M. H., Poon, V. K., Yuen, K. Y., Zheng, B. J., et al. (2009). Severe acute respiratory syndrome coronavirus $M$ protein inhibits type I interferon production by impeding the formation of TRAF3• TANK• TBK1/IKK $\epsilon$ complex. J. Biol. Chem. 284, 16202-16209. doi: 10.1074/jbc.M109. 008227

Smith, G. L., Benfield, C. T., de Motes, C. M., Mazzon, M., Ember, S. W., Ferguson, B. J., et al. (2013). Vaccinia virus immune evasion: mechanisms, virulence and immunogenicity. J. Gen. Virol. 94, 2367-2392. doi: 10.1099/vir.0. 055921-0

Srikiatkhachorn, A., Mathew, A., and Rothman, A. L. (2017). Immune-mediated cytokine storm and its role in severe dengue. Semin. Immunopathol. 39, 563 574. doi: 10.1007/s00281-017-0625-1

Stack, J., Haga, I. R., Schröder, M., Bartlett, N. W., Maloney, G., Reading, P. C., et al. (2005). Vaccinia virus protein A46R targets multiple Toll-like-interleukin1 receptor adaptors and contributes to virulence. J. Exp. Med. 201, 1007-1018. doi: $10.1084 /$ jem. 20041442

$\mathrm{Su}, \mathrm{C}$., Zhan, G., and Zheng, C. (2016). Evasion of host antiviral innate immunity by HSV-1, an update. Virol. J. 13:38. doi: 10.1186/s12985-016-0495-5

Sugai, A., Sato, H., Takayama, I., Yoneda, M., and Kai, C. (2017). Nipah and hendra virus nucleoproteins inhibit nuclear accumulation of signal transducer and activator of transcription 1 (STAT1) and STAT2 by interfering with their complex formation. J. Virol. 91:e01136-17. doi: 10.1128/JVI.01136-17

Sun, M., Hou, L., Tang, Y. D., Liu, Y., Wang, S., Wang, J., et al. (2017). Pseudorabies virus infection inhibits autophagy in permissive cells in vitro. Sci. Rep. 7:39964. doi: 10.1038/srep39964

Teijaro, J. R. (2017). Cytokine storms in infectious diseases. Semin. Immunopathol. 39, 501-503. doi: 10.1007/s00281-017-0640-2

Thoms, M., Buschauer, R., Ameismeier, M., Koepke, L., Denk, T., Hirschenberger, M., et al. (2020). Structural basis for translational shutdown and immune evasion by the Nsp1 protein of SARS-CoV-2. Science 369, 1249-1255. doi: $10.1126 /$ science.abc 8665

Thornbrough, J. M., Jha, B. K., Yount, B., Goldstein, S. A., Li, Y., Elliott, R., et al. (2016). Middle East respiratory syndrome coronavirus NS4b protein inhibits host RNase L activation. mBio 7:e0258. doi: 10.1128/mBio.00258-16 
To, K. K., Chan, J. F., Chen, H., Li, L., and Yuen, K. Y. (2013). The emergence of influenza A H7N9 in human beings 16 years after influenza A H5N1: a tale of two cities. Lancet Infect. Dis. 13, 809-821. doi: 10.1016/S1473-3099(13)70167-1

Troy, N. M., and Bosco, A. (2016). Respiratory viral infections and host responses; insights from genomics. Respir. Res. 17:156. doi: 10.1186/s12931-016-0474-9

Ulane, C. M., Rodriguez, J. J., Parisien, J. P., and Horvath, C. M. (2003). STAT3 ubiquitylation and degradation by mumps virus suppress cytokine and oncogene signaling. J. Virol. 77, 6385-6393. doi: 10.1128/jvi.77.11.6385-6393. 2003

Vabret, N., Britton, G. J., Gruber, C., Hegde, S., Kim, J., Kuksin, M., et al. (2020). Immunology of COVID-19: current state of the science. Immunity 52, 910-941. doi: 10.1016/j.immuni.2020.05.002

Van Riel, D., Den Bakker, M. A., Leijten, L. M. E., Chutinimitkul, S., Munster, V. J., De Wit, E., et al. (2010). Seasonal and pandemic human influenza viruses attach better to human upper respiratory tract epithelium than avian influenza viruses. Am. J. Pathol. 176, 1614-1618. doi: 10.2353/ajpath.2010.090949

Verrier, E. R., Yim, S. A., Heydmann, L., El Saghire, H., Bach, C., Turon-Lagot, V., et al. (2018). Hepatitis B virus evasion from cyclic guanosine monophosphateadenosine monophosphate synthase sensing in human hepatocytes. Hepatology 68, 1695-1709. doi: 10.1002/hep.30054

Virgin, H. W., Wherry, E. J., and Ahmed, R. (2009). Redefining chronic viral infection. Cell 138, 30-50. doi: 10.1016/j.cell.2009.06.036

Wang, D., Chen, J., Yu, C., Zhu, X., Xu, S., Fang, L., et al. (2019). Porcine reproductive and respiratory syndrome virus nsp11 antagonizes type I interferon signaling by targeting IRF9. J. Virol. 93:e00623-19. doi: 10.1128/JVI. 00623-19

Wang, S., Chi, X., Wei, H., Chen, Y., Chen, Z., Huang, S., et al. (2014). Influenza $A$ virus-induced degradation of eukaryotic translation initiation factor $4 \mathrm{~B}$ contributes to viral replication by suppressing IFITM3 protein expression. J. Virol. 88, 8375-8385. doi: 10.1128/jvi.00126-14

Wang, X., Li, M., Zheng, H., Muster, T., Palese, P., Beg, A. A., et al. (2000). Influenza A virus NS1 protein prevents activation of NF- $\kappa \mathrm{B}$ and induction of alpha/beta interferon. J. Virol. 74, 11566-11573. doi: 10.1128/JVI.74.24.11566-11573.2000

Wauquier, N., Becquart, P., Padilla, C., Baize, S., and Leroy, E. M. (2010). Human fatal zaire ebola virus infection is associated with an aberrant innate immunity and with massive lymphocyte apoptosis. PLoS Negl. Trop. Dis. 4:e837. doi: 10.1371/journal.pntd.0000837

Weber, F., Wagner, V., Rasmussen, S. B., Hartmann, R., and Paludan, S. R. (2006). Double-stranded RNA is produced by positive-strand RNA viruses and DNA viruses but not in detectable amounts by negative-strand RNA viruses. J. Virol. 80, 5059-5064. doi: 10.1128/JVI.80.10.5059

Whitton, J. L., Cornell, C. T., and Feuer, R. (2005). Host and virus determinants of picornavirus pathogenesis and tropism. Nat. Rev. Microbiol. 3, 765-776. doi: $10.1038 /$ nrmicro1284
World Health Organization (2018). Available online at: http://www.who.int/csr/ sars/country/table2004_04_21/en/ (accessed on October 19, 2020).

Wu, X., Qi, X., Qu, B., Zhang, Z., Liang, M., Li, C., et al. (2014). Evasion of antiviral immunity through sequestering of TBK1/IKK $8 /$ IRF3 into viral inclusion bodies. J. Virol. 88, 3067-3076. doi: 10.1128/JVI.03510- 13

Wu, Y., Liu, Q., Zhou, J., Xie, W., Chen, C., Wang, Z., et al. (2017). Zika virus evades interferon-mediated antiviral response through the co-operation of multiple nonstructural proteins in vitro. Cell Discov. 3:17006. doi: 10.1038/celldisc. 2017.6

Xie, M., Xuan, B., Shan, J., Pan, D., Sun, Y., Shan, Z., et al. (2015). Human cytomegalovirus exploits interferon-induced transmembrane proteins to facilitate morphogenesis of the virion assembly compartment. J. Virol. 89, 3049-3061. doi: 10.1128/jvi.03416-14

Yang, C., Zhao, X., Sun, D., Yang, L., Chong, C., Pan, Y., et al. (2016). Interferon alpha (IFN $\alpha$ )-induced TRIM22 interrupts HCV replication by ubiquitinating NS5A. Cell. Mol. Immunol. 13, 94-102. doi: 10.1038/cmi.20 14.131

Yokota, S., Yokosawa, N., Okabayashi, T., Suzutani, T., Miura, S., Jimbow, K., et al. (2004). Induction of suppressor of cytokine signaling-3 by herpes simplex virus type 1 contributes to inhibition of the interferon signaling pathway. J. Virol. 78, 6282-6286. doi: 10.1128/JVI.78.12.6282-6286. 2004

Zhu, H., and Zheng, C. (2020). The race between host antiviral innate immunity and the immune evasion strategies of herpes simplex virus 1. Microbiol. Mol. Biol. Rev. 84:e00099-20. doi: 10.1128/MMBR.00099-20

Zhu, X., Wang, D., Zhou, J., Pan, T., Chen, J., Yang, Y., et al. (2017). Porcine deltacoronavirus nsp5 antagonizes type I interferon signaling by cleaving STAT2. J. Virol. 91:e00003-17. doi: 10.1128/JVI.00003-17

Zuberbier, T., Aberer, W., Asero, R., Abdul Latiff, A. H., Baker, D., Ballmer-Weber, B., et al. (2018). The EAACI/GA ${ }^{2} \mathrm{LEN} / \mathrm{EDF} / \mathrm{WAO}$ guideline for the definition, classification, diagnosis and management of urticarial. Allergy 73, 1393-1414. doi: $10.1111 /$ all.13397

Conflict of Interest: The authors declare that the research was conducted in the absence of any commercial or financial relationships that could be construed as a potential conflict of interest.

Copyright (c) 2021 Rai, Shrestha, Yang, Chen, Liu, Maarouf and Chen. This is an open-access article distributed under the terms of the Creative Commons Attribution License (CC BY). The use, distribution or reproduction in other forums is permitted, provided the original author(s) and the copyright owner(s) are credited and that the original publication in this journal is cited, in accordance with accepted academic practice. No use, distribution or reproduction is permitted which does not comply with these terms. 